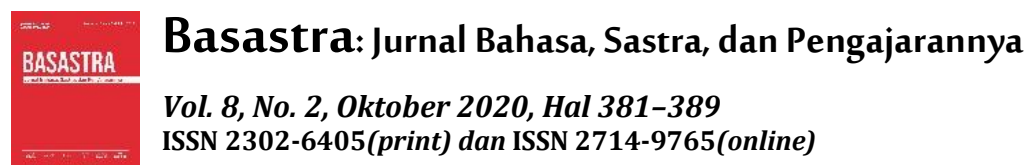

\title{
PEMBELAJARAN TEKS EKSPLANASI BERDASARKAN KURIKULUM 2013 SISWA KELAS VIII SMP NEGERI 8 SURAKARTA
}

\author{
Dyah Ayu Pramesti ${ }^{1}$, Nugraheni Eko Wardani ${ }^{2}$, Chafit Ulya ${ }^{3}$ \\ ${ }^{1}$ Universitas Sebelas Maret Surakarta \\ Email:dapramesti22@gmail.com¹,nugraheniekowardani_99@yahoo.co.id², \\ Chafit@staff.uns.ac.id ${ }^{2}$
}

\begin{abstract}
Abstrak: Tujuan penelitian ini untuk mendeskripsikan pembelajaran teks eksplanasi berdasarkan kurikulum 2013 siswa kelas VIIII SMP Negeri 8 Surakarta. Penelitian ini menggunakan metode penelitian deskriptif kualitatif. Hasil penelitian menunjukkan bahwa guru telah melakukan tiga tahapan dalam pembelajaran, yaitu perencanaan, pelaksanaan, dan penilaian pembelajaran. Pada perencanaan pembelajaran tertuang dalam rencana pelaksanaan pembelajaran (RPP) yang digunakan oleh guru dengan mengikuti format RPP kurikulum 2013. Pada pelaksanaan pembelajaran ditemukan bahwa beberapa kegiatan guru telah memenuhi konsep pembelajaran kurikulum 2013, yakni telah dilakukannya kegiatan apersepsi, kegiatan inti, dan kegiatan penutup. Pada penilaian pembelajaran menyusun teks eksplanasi, terlihat guru hanya menilai aspek pengetahuan saja, yakni siswa diberi tugas menyusun teks eskplanasi secara individu.
\end{abstract}

Kata Kunci:ekplanasi, kurikulum 2013, pembelajaran

\section{EXPLANATION TEXT LEARNING BASED ON 2013 CURRICULUM CLASS VIII STUDENTS OF SMP NEGERI 8 SURAKARTA}

\begin{abstract}
The purpose of this study was to describe explanatory text learning based on the 2013 curriculum for class VIII students of SMP Negeri 8 Surakarta. This research uses descriptive qualitative research methods. The results showed that the teacher had carried out three stages in learning, namely planning, implementing, and assessing learning. In the lesson plan, it is stated in the lesson plan (RPP) that is used by the teacher by following the RPP curriculum 2013 format. In implementing the learning process, it was found that some of the teacher's activities had fulfilled the concept of learning in the 2013 curriculum, namely apperception activities, core activities, and closing activities. In the assessment of learning to compile explanatory text, it appears that the teacher only assesses aspects of knowledge, namely students are given the task of compiling explanatory text individually.
\end{abstract}

Keywords: explanation, 2013 curriculum, learning

\section{PENDAHULUAN}

Pembelajaran meruakan segala upaya atau usaha yang dilakukan oleh guru agar terjadi proses belajar pada diri siswa. Pembelajaran sebagai interaksi antara guru dan siswa untuk mencapai tujuan dengan menggunakan metode, media, dan sumber belajar yang sesuai dengan tujuan (Fadillah, 2014: 173).

BASASTRA Jurnal Bahasa, Sastra, dan Pengajarannya 
Pembelajaran menekankan cara-cara yang digunakan untuk mencapai tujuan dan berkaitan dengan cara mengorganisasikan materi pelajaran, menyampaikan materi pelajaran dan mengelola pembelajaran (Sutikno, 2013: 31-32). Pembelajaran berdasar-kan kurikulum 2013 menekankan pembelajaran sebagai proses ilmiah dengan pedekatan saintifik. Jenis materi pembelajaran dalam kurikulum 2013 dikelompokkan menjadi fakta, konsep, prinsip, dan prosedur (Winaya, 2015: 2). Dalam kurikulum 2013 sistem penilaian yang digunakan adalah penilaian autentik yang mencakup penilaian sikap, penge-tahuan, dan keterampilan (Mardiana, 2017: 46).

Menurut Nur'aini, Saddhono, \& Ulya (2015) penerapan kurikulum 2013 khususnya pada pembelajaran bahasa Indonesia saat ini menggunakan teks sebagai sarana pembelajarannya, baik lisan maupun tulis dengan menempat-kan bahasa Indonesia sebagai sumber pengetahuan. Pembelajaran Bahasa Indonesia memiliki empat keterampilan berbahasa yang harus dimiliki oleh siswa yaitu keterampilan mendengarkan, berbicara, membaca, dan menulis (Dalman, 2012:3).

Teks dalam pelajaran bahasa Indonesia sangat beraneka, salah satunya yaitu teks eksplanasi karena menulis teks eksplanasi dianggap dapat meningkatkan kreatifitas siswa. Guru perlu mengembangkan pelaksanaan pembelajaran menulis teks eksplanasi untuk meningkatkan motivasi dan hasil keterampilan menulis teks eksplanasi. Guru perlu mengembangkan pelaksanaan pembelajaran menulis teks eksplanasi untuk meningkatkan motivasi dan hasil keterampilan menulis teks eksplanasi (Andyani, Saddhono, \& Mujyanto, 2016).

Menurut Tarigan (2008: 22), menulis sangat penting bagi pendidikan karena memudahkan para pelajar berpikir. Juga dapat menolong kita berpikir secara kritis, serta dengan menulis dapat membantu kita untuk menjelaskan apa yang ada dalam pikiran kita. Berdasarkan silabus mata pelajaran Bahasa Indonesia yang sesuai dengan kurikulum 2013, salah satu tema pembelajaran Bahasa Indonesia adalah menulis teks eksplanasi yang terdapat pada Kompetensi Dasar (KD) 4.10 Meyusun teks eksplanasi dengan karakteristik teks yang akan di buat baik secara lisan maupun tulisan.

Teks eksplanasi merupakan teks yang berisi penjelasan tentang proses yang berhubungan dengan fenomena-fenomena alam, sosial, ilmu pengetahuan, dan budaya. Teks eksplanasi berasal dari pertanyaan penulis terkait 'mengapa' dan 'bagaimana' suatu fenomena terjadi. Teks eksplanasi bertujuan untuk menjelaskanproses pembentukan atau kegiatan yang terkait dengan fenomena-fenomena alam, sosial, ilmu pengetahuan, atau budaya (Priyatni, 2014: 82). 
Menurut Sutikno (2013: 5051), untuk menunjang terlaksananya suatu kegiatan pembelajaran dengan baik, maka peran guru sangatlah penting. Tugas guru adalah membantu peserta didik agar mampu melakukan adaptasi terhadap berbagai tantangan kehidupan serta desakan yang berkembang dalam dirinya. Dengan kata lain, tugas utama guru adalah membelajarkan siswa, yaitu mengkondisikan siswa agar belajar aktif sehingga potensi dirinya dapat berkembang dengan maksimal. Agar hal tersebut dapat terwujud, guru seharusnya mengetahui bagaimana cara siswa belajar dan menguasai berbagai cara membelajarkan siswa. Selain peran guru, dalam kegiatan pembelajaran, terdapat pula aktivitas siswa. Terdapat beberapa aktivitas utama yang harus dilakukan oleh siswa dalam pembelajaran, yaitu seperti aktivitas mengamati, menanya, mengumpulkan data, menalar, dan mengomunikasikan. Hal tersebut pada pembelajaran teks eksplanasi siswa kelas VIII diintegrasikan menjadi satu dan saling berkaitan.

Penelitian ini fokus pada tiga komponen pembelajaran yaitu perencanaan, pelaksanaan, serta evaluasi. Karena tiga komponen pembelajaran tersebut merupakan komponen pembelajaran yang masih bisa diusahakan secara maksimal oleh guru ketika proses kegiatan belajar mengajar berlangsung untuk keberhasilan pembelajaran bahasa Indonesia berbasis teks, pada khususnya pembelajaran teks eksplanasi. Penelitian ini bertujuan untuk mendeskripsikan perencanaan, pelaksanaan dan evaluasi yang diaplikasikan dalam pembelajaran teks eksplanasi.

Untuk mengetahui aktivitas siswa dan guru dalam pembelajaran teks eksplanasi siswa kelas VIII, penulis memilih SMP Negeri 8 Surakarta sebagai tempat penelitian. Penulis memilih sekolah tersebut untuk tempat penelitian karena salah satu sekolah yang ditunjuk untuk melaksanakan pembelajaran yang menggunakan kurikulum 2013.Di sekolahini banyak memiliki guru-guru senior yang telah lama mengajar, salah satunya adalah ibu Titik Haryani, S.Pd. sebagai guru mata pelajaran Bahasa Indonesia. IbuTitik juga telah mengikuti pelatihan implementasi kurikulum 2013 sebanyak dua kali pelatihan. SMP Negeri 8 Surakarta juga termasuk salah satu sekolah favorit di Kota Surakarta. Berdasarkan uraian di atas, penulis merasa penting meneliti Pembelajaran Teks Eksplanasi BerdasarkanKurikulum 2013 pada Siswa Kelas VIII SMP Negeri 8 Surakarta.

\section{METODE}

Desain penelitian yang digunakan dalam penelitian ini adalah deskriptif kualitatif. Metode penelitian deskriptif kualitatif sering disebut metode penelitian naturalistik, karena penelitiannya dilakukan pada kondisi yang alamiah. Obyek yang alamiah adalah obyek yang berkembang apa 
adanya, tidak dimanipulasi oleh peneliti, dan kehadiran peneliti tidak begitu mempengaruhi dinamika pada obyek tersebut. Analisis data bersifat induk/kualitatif, dan hasil penelitian kualitatif lebih menekankan makna dari pada generalisasi (Sugiyono, 2013: 14-15).

Sumber data pada penelitian ini berupa perencanaan pembelajaran yang berupa RPP dan silabus yang digunakan guru mata pelajaran bahasa Indonesia SMP Negeri 8 Surakarta, pelaksanaan pembelajaran teks eksplanasi siswa kelas VIII SMP Negeri 8 Surakarta, dan penilaian dalam pembelajaran teks eksplanasiSMP Negeri 8 Surakarta tahun pelajaran 2019/2020.

Teknik yang digunakan untuk mendapatkan data pembelajaran menyusun teks eksplanasi, yakni observasi, wawancara, dokumentasi, dan triangulasi. Teknik analisis data yang digunakan pada penelitian ini mengacu pada teknik analisis selama penelitian di lapangan, menggunakan model Miles dan Huberman. Berdasarkan model Miles dan Huberman (1992: 15-21), yaitu analisis data model interaktif dengan tahapan reduksi data, penyajian data, dan verifikasi atau penarikan kesimpulan

\section{HASIL DAN PEMBAHASAN}

Hasil dan pembahasan penelitian mengenai pembelajaran menyusun teks eksplanasi menunjukkan tiga tahapan yang dilalui dalam pembelajaran, yaitu perencanaan, pelaksanaan, dan evaluasi.

\section{Perencanaan Pembelajaran}

Perencanaan merupakan suatu cara untuk membuat kegiatan berjalan baik dengan langkah untuk mencapai tujuan yang ditetapkan (Uno, 2012: 1).Rencana pelaksanaan pembelajaran disusun setiap kompetensi dasar yang dilakukan dalam satu kali pertemuan atau lebih, guru merencanakan RPP disesuaikan dengan jadwal pada setiap satuan pendidikan (Rusman, 2014: 5).

Perencanaan pembelajaran menyusun teks eksplanasi sudah cukup baik walaupun ada beberapa hal yang tidak sesuai dengan pelaksanaan yang akan dilaksanakan.

\section{Identitas Mata Pelajaran}

Berdasarkan pengamatan, RPP yang digunakan sudah memuat satuan pendidikan, mata pelajaran, kelas/semester, materi pokok, dan alokasi waktu. Namun, dalam penulisan alokasi waktu belum sesuai dengan format penulisan alokasi waktu.

\section{Perumusan Indikator}

Berdasarkan pengamatan, perumusan indikator dalamRPP yag digunakan oleh guru sudah sesuai dengan format RPP permendikbud.

\section{Tujuan Pembelajaran}

Tujuan pembelajaran yang dirumuskan belum terdapat degree atau tingkat kemampuan yang diharapkan, serta belum memuat tujuan pembelajaran yang digunakan untuk kom-petensi dasar 4.10yaitu menyusun teks eksplanasi.

\section{Pemilihan Materi Ajar}

Materi ajar yang dipilih dalam RPP yang digunakan guru belum 
sesuai dengan tujuan pem-belajaran, bahkan tidak sesuai dengan kompetensi dasar yang hendak dicapai.

\section{Pemilihan Sumber Belajar}

Sumber belajar yang dimuat sudah sesuai dengan KI dan KD, memuat aspek sikap, pengetahuan, dan keterampilan, serta sesuai dengan pendekatan saintifik, yakni menggunakan buku yang dibagikan oleh pemerintah.

\section{Pemilihan Media Belajar}

Media belajar yan diplih sudah sesuai dengan karakteristik peserta didik, yakni meng-gunakan contoh teks eksplanasi dan gambar tsunami.

\section{Model Pembelajaran}

Berdasarkan pengamatan, model pembelajaran yang digunakan oleh guru hanya model penemuan (discovery learning).

\section{Skenario Pembelajaran}

Skenario pembelajaran yang dimuat sudah ada kegiatan pendahuluan, inti, dan penutup serta sudah memuat pendekatan saintifik yang terdiri dari aktivitas 5M. Namun, dalam RPP tersebut tidak dituliskan secara tepat aktivitas $5 \mathrm{M}$ tersebut.

\section{Penilaian}

Penilaian yang dimuat dalam RPP menyusun teks eksplanasi belum mencantumkan rubrik penilaian yang akan digunakan, RPP tersebut hanya memuat garis besar saja penilaian yang dipakai.
Hambatan dan Solusi pada Perencanaan Pembelajaran Menyusun Teks Eksplanasi diperoleh dari hasil wawancara mendalam yang peneliti lakukan terhadap guru mata pelajaran bahasa Indonesia, guru masih bingung dalam menyusun sendiri RPP yang akan digunakan dalam pembelajaran menyusun teks eksplanasi. Solusi yang ditempuh adalah dengan menggunakan RPP yang beliau dapat dari pelatihan yang pernah diikuti.

\section{Pelaksanaan Pembelajaran}

Pelaksanaan pembelajaran menyusun teks eksplanasi oleh guru dilaksanakan dalam tiga kegiatan, yaitu kegiatan pendahuluan, kegiatan inti, dan kegiatan penutup.

Suprihatiningrum (2013) menyatakan bahwa pelaksanaan pembelajaran merupakan suatu cara untuk menyajikan, menjabarkan, memberi contoh, dan memberi latihan isi dari pelajaran yang dilakukan oleh guru atau pendidik kepada siswa guna mencapai tujuan tertentu.

Dalam kegiatan pendahuluan, guru harus melakukan dua kegiatan pokok, yakni apersepsi dan motivasi, serta penyampaian kompetensi dan rencana kegiatan.

\section{Apersepsi dan Motivasi}

Dalam kegiatan apersepsi dan motivasi, guru telah melakukannya dengan baik, yakni mengaitkan pembelajaran sekarang dengan pengalaman peserta didik atau pembelajaran sebelumnya, mengajukan per-tanyaan menantang

BASASTRA Jurnal Bahasa, Sastra, dan Pengajarannya

Volume 8 Nomor 2, Oktober 2020, P-ISSN 2302-6405, E-ISSN 2714-9765 
kepada peserta didik, dan mendemonstrasikan sesuatu yang terkait dengan materi pelajaran. Namun, sangat disayangkan guru tidak menyampaikan manfaat materi pelajaran.

\section{Penyampaian Kompetensi dan} Rencana Kegiatan

Berdasarkan pengamatan, guru hanya menyampaikan rencana kegiatan, yakni menyampaikan bahwa peserta didik nantinya akan menyusun teks eksplanasi secara individu.

Kegiatan inti merupakan kegiatan yang sangat penting pada pelaksanaan pembelajaran. Dalam kegiatan inti guru haruslah menguasai materi pembelajaran,menerapkan strategi pembelajaran yang mendidik, menerapkan pendekatan saintifik, memanfaatkan sumber belajar, melibatkan peserta didik dalam pembelajaran, dan menggunakan bahasa yang benar dan tepat dalam pembelajaran.

\section{Penguasaan Materi Pelajaran}

Berdasarkan pengamatan, guru terlihat sudah menguasai pelajaran. Guru sudah mampu menyesuaikan materi dengan tujuan pembelajaran yang sebenarnya, walaupun di dalam RPP tujuan pembelajarannya kurang tepat. Materi yang disampaikan pun dibahas dengan tepat dan sistematis.

\section{Penerapan StrategiPembelajaran Mendidik}

Berdasarkan pengamatan, guru
sudah menerapkan strategi
pembelajaran yang mendidik dengan
cukup baik, yakni melaksanakan

pembelajaran se-suai dengan kompetensi yang akan dicapai, memfasilitasi ke-giatan yang memuat komponen eksplorasi, elaborasi, dan kon-firmasi. Bukan hanya itu saja, guru juga telah melaksanakan pembelajaran secara runtut, menguasai kelas, melaksanakan pembelajaran yang bersifat kontekstual, dan melaksanakan pembelajaran yang memungkinkan tumbuhnya kebiasaan positif. Namun, guru tidak melaksana-kan pembelajaran sesuai dengan alokasi waktu yang direncana-kan dalam RPP.

\section{Penerapan Pendekatan Saintifik}

Berdasarkan pengamatan, guru sudah menerapkan pendekatan sintifik. Kegiatan yang dilaku-kan guru dalam menerapkan pendekatan saintifik adalah memberikan pertanyaan mengapa dan bagaimana, memancing siswa untuk bertanya, mem-fasilitasi siswa untuk mencoba, memfasilitasi siswa untuk mengamati, memfasilitasi siswa untuk menalar, memfasilitasi siswa untuk menganalisis, tetapi guru tidakmenyajikan kegiatan peserta didik untuk ber-komunikasi. Hal tersebut di-karenakan waktunya kurang mencukupi.

Pemanfaatan Sumber Belajar atau Media dalam Pembelajaran

Berdasarkan pengamatan, guru sudah memanfaatkan sumber belajar atau media dalam pem-belajaran dengan cukup baik. Hal tersebut ditunjukkan dengan keterampilan guru dalam meng-gunakan sumber belajar dan media pembelajaran, yakni guru

BASASTRA Jurnal Bahasa, Sastra, dan Pengajarannya

Volume 8 Nomor 2, Oktober 2020, P-ISSN 2302-6405, E-ISSN 2714-9765 
menggunakan buku Wahana Pengetahuan, dan guru me-nayangkan media video pembelajaran tentang teks eksplanasi. Memanfaatkan sumber belajar/media dalam pembelajaran tersebut terlihat dapat menghasilkan pesan yang menarik dan melibatkan peserta didik.

\section{Pelibatan Siswa dalam Pembelajaran}

Berdasarkan pengamatan, guru sudah melibatkan siswa dalam pembelajaran. Pelibatan siswa dalam pembelajaran tampak saat guru mampu menumbuhkan partisipasi aktif peserta didik, merespon aktif partisipasi peserta didik, menunjukkan sikap terbuka terhadap respon peserta didik, menumbuhkan hubungan antarpribadi yang kondusif, dan menumbuhkan keceriaan atau antusiasme siswa.

Kegiatan penutup adalah kegiatan terakhir dalam pelaksanaan pembelajaran. Dalamkegiatan ini guru hanya mengumpulkan hasil kerja siswa serta melaksanakan tindak lanjut dengan memberikan arahan kegiatan berikutnya. Guru tidak melakukan refleksi atau membuat rangkuman dan memberikan tes lisan atau tulisan karena waktu yang tidak mencukupi.

\section{Evaluasi Pembelajaran}

Menurut Arikunto (2012: 2) evaluasi adalah serangkaian kegiatan yang bertujuan untuk mengukur sebuah keberhasilan dalam program pendidikan. Purwanto (2010: 58) juga menyatakan bahwa evaluasi merupakan proses menilai sejauhmana tujuan pendidikan tersebut dapat dicapai, hal tersebut lebih meninjau pengertian evaluasi dalam konteks tujuan.

Metode evaluasi yang digunakan dalam proses pembelajaran dibedakan menjadi dua macam bentuk, yaitu dengan tes dan nontes (Sukardi, 2015: 8). Berdasarkan pengamatan peneliti, dalam kegiatan penilaian pembelajaran menyusun teks eskplanasi guru hanya melakukan penilaian pengetahuan saja. Penilaian pengetahuan dilakukan dengan menggunakan teknik tertulis.

\section{SIMPULAN}

Berdasarkan hasil penelitian dapat disimpulkan bahwa pembelajaran menyusun teks eksplanasi pada siswa kelas VIII SMP Negeri 8 Surakarta telah dilakukan dalam tiga tahap, yaitu perencanaan, pelaksanaan, dan evaluasi. Pada tahap perencanaan, guru sudah melakukan tahapan perencanaan pembelajaran yang dibuatdengan menyiapkan silabus, selain itu memperisapkan RPP yang komponen RPP terdapat dalam instrumen pada perencanaan pembelajaran. Meskipun terdapat beberapa indikator yang tidak termuat dalam perencanaan pem-belajaran, serta terdapat ketidak-sesuaian antara RPP dengan materi yang dibelajarkan.

$$
\text { Pada pelaksanaan }
$$
pembelajaran menyusun teks eksplanasi guru sudah melaksanakan tiga tahap dalam pelaksanaan pembelajaran, yaitu kegiatan 
pendahuluan, kegiatan inti, dan kegiatan penutup. Dalam melaksanakan kegiatan pendahuluan ada beberapa indikator yang tidak dilaksanakan oleh guru, yakni tidak menyampaikan manfaat materi pelajaran dan tidak menyampaikan kemampuan yang akan dicapai peserta didik. Dalam melaksanakan kegiatan inti pembelajaran guru diharuskan menguasai materi pembelajaran, menerapkan strategi pembelajaran yang mendidik, menerapkan pendekatan saintifik dalam pembelajaran,memanfaatkan sumber belajar, melibatkan peserta didik dalam pembelajaran dan menggunakan bahasa yang benar dan tepat. Namun, terdapat satu indikator dalam penerapan pendekatan saintifik yang tidak dilaksanakan oleh guru, yakni tidak menyajikan kegiatan peserta didik untuk berkomunikasi. Selain itu, guru juga telah melakukan kegiatan penutup berupa mengumpulkan hasil kerja sebagai bahan portofolio dan melaksanakan tindak lanjut dengan memberikan arahan kegiatan berikutnya dan tugas pengayaan. evaluasi pembelajaran menyusun teks eksplanasi yang dilakukan oleh guru belum mencerminkan penilaian autentik kurikulum 2013 dengan baik, yakni menilai aspek sikap, pengetahuan, dan keterampilan. Pada pembelajaran menyusun teks eksplanasi guru hanya menilai aspek pengetahuan saja, yakni menilai hasil kerja siswa menyusun teks eksplanasi.

\section{REFERENSI}

Andayani, Saddhono, K. \& Mujiyanto, Y. (2016). Peningkatan Kemampuan Menulis Teks Eksplanasi Dengan Menggunakan Media Audiovisual pada Siswa Sekolah Menengah Pertama. Jurnal Basastra,4 (2), 161-174.

Arikunto, S. (2012). Dasar-Dasar Evaluasi Pendidikan. Jakarta: Bumi Aksara.

Dalman. (2012). Keterampilan Menulis. Jakarta: PT Raja Grafindo persada.

Fadlillah, M. (2014). Implementasi Kurikulum 2013. Yogyakarta: ArRuzz Media.

Mardiana, S. (2017). Implementasi Kurikulum 2013 Dalam Pembelajaran Sejarah Di SMA Negeri 1 Metro. Jurnal Historia, 5 (1), 45-54.

Miles, M.B \& Hubberman, A.M. (1992).Analisis Data Kualitatif: Buku Sumber tentang MetodeMetode Baru (Terjemahan: Tjeptjep Rohendi Rohidi). Jakarta: Universitas Indonesia.

Priyatni, E.T. (2014). Desain Pembelajaran Bahasa Indonesia dalam Kurikulum 2013. Jakarta: Bumi Aksara.

Purwanto, N. (2010). Prinsip-prinsip dan Teknik Evaluasi Pengajaran. Bandung: Remaja Rosdiyakarya.

Rusman. (2014). Model-model Pembelajaran. Bandung: CV Bina Media.

Sugiyono. (2013). Metode Penelitian Pendidikan Pendekatan Kuantitatif, Kualitatif, dan $R \& D$.Bandung: Alfabeta.

Sukardi. (2015). Evaluasi Pendidikan: Prinsip dan Operasionalnya. Jakarta: Bumi Aksara. 
Suprihatiningrum, J. (2013). Strategi

Pembelajaran. Yogyakarta: Ar-

Ruzz Media.

Sutikno, S. (2013). Belajar dan Pembelajaran. Lombok: Holistica.

Tarigan, H.G. (2008). Menulis.Bandung : Angkasa.

Uno, H B. (2012). Perencanaan Pembelajaran. Jakarta: Bumi Aksara.

Winaya, I.K., dkk. (2015). Analisis Rencana Pelaksanaan Pembelajaran Menurut Kurikulum 2013 Kelas IV SD No.4 Banyusari. E-Journal PGSD Universitas Pendidikan Ganesha, 3 (1).

Nur'aini, Saddhono, K. \& Ulya, C. (2015). Implementasi Kurikulum 2013 Pada Pembelajaran Menulis Teks Eksposisi (Studi Kasus di Kelas $\mathrm{X}$ SMK NEGERI 1 Karanganyar). Jurnal Basatra, (3), 1. 